\title{
Commentary: Mental Health Act reform must include carers
}

\section{Nuwan Dissanayaka*}

*Leeds and York Partnership NHS Foundations Trust, Leeds LS15 8ZB, UK.

Article Info

\section{Article Notes}

Received: February 14, 2018

Accepted: March 05, 2018

\section{*Correspondence:}

Dr. Nuwan Dissanayaka, Leeds and York Partnership NHS

Foundations Trust, Leeds LS15 8ZB, UK,

E-mail address: n.dissanayaka@nhs.net;

C 2018 Dissanayaka N. This article is distributed under the terms of the Creative Commons Attribution 4.0 International License.
The Mental Health Act 1983, the primary piece of legislation that covers the assessment, treatment and rights of people with a mental health disorder in England and Wales, is currently under review.

As part of this review the identification of "The Nearest Relative" is being considered. The term nearest relative is not the same as "next of kin" but instead has a specific meaning; it refers to the person identified to provide an important safeguard for the rights of people subject to the Mental Health Act. This individual has various rights as detailed in the article.

Dissatisfaction has been expressed about the way in which the nearest relative is currently identified by means of the following hierarchy:

1. Husband, wife or civil partner (including cohabitee for more than 6 months).

2. Son or daughter

3. Father or mother (an unmarried father must have parental responsibility in order to be nearest relative)

4. Brother or sister

5. Grandparent

6. Grandchild

7. Uncle or aunt

8. Nephew or niece

This is a cause for concern which was highlighted by the Mental Health Act Alliance, a coalition of more than 65 organisations formed in 2000, who have a shared goal of campaigning for reform of the Mental Health Act. In their "Agenda for Reform" they reported that $86 \%$ of respondents to their survey felt that it was very important that an individual is able to specify which individual close to them (e.g. partner, friend or family member) is statutorily involved in decisions about their mental health care and treatment.

However, a further finding from respondents was of dissatisfaction with the way they felt the system was abused by local authorities and mental health trusts. A quote from the report from a carer stated "Her psychiatrist and social workers used the Mental Health Act to displace me as nearest relative and put my mum in care. They abused the Act and my mum was subsequently abused in care." 
It is my clinical experience that the rights of the nearest relative are inconsistently respected. The Mental Health Act review provides us with an opportunity to correct the power imbalance that can exist between clinician and carer by enhancing the safeguards that ensure effective consultation and involvement in care, address the complex issue of confidentiality when a patient lacks capacity and hopefully reduce the ensuing conflict that can arise.

1.Department of Health. Mental Health Act. ((accessed Dec 11, 2017).) https://www.legislation.gov.uk/ukpga/2007/12/pdfs/ ukpga_20070012_en.pdf

Date: 2007

2. Mental Health Alliance. A Mental Health Act fit for tomorrow. An agenda for reform. ((accessed Dec 6, 2017).)

http://www.mentalhealthalliance.org.uk/news/A_ Mental_Health_Act_Fit_For_Tomorrow.pdf

Date: June 2017 